\title{
Ciclo anual da Gametogênese de Anomalocardia brasiliana (Gmelin, 1791) (Mollusca Bivalvia)
}

\author{
WALTER NARCHI \\ Departamento de Zoologia, Instituto de Biociências \\ Universidade de são Paulo.
}

\begin{abstract}
A B S T R A C T
Annual Cycle of Gametogenesis of Anomalocardia brasiliana (Gmelin, 1791)

(Mollusca Bivalvia).

This paper deals with the changes in gonadal development in male and female of Anomalocardia brasiliana (Gmelin, 1791).

There are two periods of gametogenesis, in autumm and in spring, being the degree of maturation longer in the later one. The spawning cycle, however, is practically continuous, without any period of sexual rest.
\end{abstract}

\section{N T R O D U Ç Ã O}

Afora os trabalhos de Narchi (1965, 1972 e 1974) sobre anatomia funcional de Anomalocardia brasiliana (Gmelin, 1791) quase nada é conhecido da biologia deste bivalve. Esses animais são citados apenas em trabalhos de sistemática ou em listas de distribuição de espécies de moluscos do litoral brasileiro.

A reprodução, o desenvolvimento e o ciclo sexual são pontos de vital importância na pesquisa da sua biologia, pois sem indicações seguras sobre o ritmo e ciclo reprodutivo outros aspectos biológicos seriam dificilmente compreendidos.

Sobre reprodução de $A$. brasiliana conhecem-se apenas constatações fortuitas e o problema ainda não foi abordado de maneira pormenorizada e sistemática. Em outros gêneros como Venus, Mercenaria e Tivela há numerosas informações sobre o ciclo sexual, principalmente no hemisfério norte (Atlântico Norte e Pacífico).

Havendo o risco de coletas indiscriminadas e constantes poderem levar as reservas naturais dos "berbigões" à extinção, deve ser obtido o maior número possível de dados biológicos para estabelecer a manutenção 
das reservas, com ulterior repovoamento de outras regiões, como é feito atualmente com ostras na Costa Pacifica dos Estados Unidos.

O objetivo principal deste trabalho foi o estudo do ciclo sexual de A. brasiliana, através da histologia das gônadas como aspecto primordial.

Nada é conhecido na literatura especializada sobre a histologia da gônada desses animais e, em geral, muito pouco dos Veneridae. Graças a inúmeras pesquisas com mexilhões e ostras, os Filibranchiata são muito melhor conhecidos nesse aspecto.

Para o estudo do ciclo sexual é imprescindível a análise microscópica dos vários estágios das gônadas. É impossível nesta espécie, assim como em Spondylus, Pecten, Chlamys e Katelysia (Nielsen, 1964), estabelecer a olho nu pelas características da massa visceral, a natureza da gônada ou as diferentes etapas da gametogênese, como observaram Chipperfield (1953) e Lubett (1959) para o gênero Mytilus. Em oposição a este gênero, as gônadas de A. brasiliana não se estendem dentro do manto. Em ambos os sexos elas consistem de uma rede de tubos ramificados, com um duto comum, o qual se abre para o exterior numa pequena papila, situada próximo à porção anterior do rim. As gônadas são pares e em A. brasiliana quando maduras preenchem completamente todo espaço disponível, inclusive a região superior, tomando toda a porção do umbo.

\section{MATERIAL E MÉTODOS}

Os animais estudados foram provenientes da Ponta da Praia, Baía de Santos $\left(23^{\circ} 47^{\prime} \mathrm{S}, 46^{\circ} 22^{\prime} \mathrm{W}\right)$, onde eles vivem enterrados em pequena profundidade. Foram coletados em baixios areno-lodosos defronte ao desembarcadouro aí existente, juntamente com os moluscos Chione intrapurpurea, C. granulata e Nassarius sp.

Para coletar o animal usei o processo empregado pelos caiçaras, isto é, com as mãos, durante a maré baixa. $\mathrm{Na}$ areia são reconhecíveis os orifícios deixados pelos sifões e que, pela pressão do nosso peso, emitem jatos de água, de onde provém o nome popular "mija-mija" Nas marés altas os animais foram coletados com um ancinho de pontas recurvadas, cujos espaços entre as hastes eram suficientemente estreitos para retê-los.

Para o estudo da gametogênese parte da massa visceral, com as gônadas, foi fixada em Bouin, Susa e formol, dos quais o primeiro foi o mais apropriado. Cortes de $5 \mu \mathrm{m}$ em média foram feitos e corados com hematoxilina-eosina, a fim de se observar a estrutura do órgão durante as diferentes fases do ciclo sexual e, com hematoxilina férrica de Heidenhein, para análise das variações nucleares durante a gametogênese.

\section{Histogênese das gônadas}

Nielsen (1964) classificou o estado de desenvolvimento das gônadas em vários estágios, seguindo o modelo de Orton, Southward \& Dodd (1956) para Patella vulgata. Como esta classificação refere-se, em parte, ao aspecto macroscópico, preferi seguir a de Chipperfield (1953), com algumas modificações, embora as gônadas de $A$. brasiliana situem-se na massa visceral e não no manto. Ela abrange os estágios I, II e III, caracterizados da seguinte forma: 
Estágio I: Esboços foliculares presentes.

Estágio II: Processa-se a multiplicação das gônias.

Estágio III: Maturidade sexual já atingida e os espécimes encontram-se em diferentes estágios de emissão de gametas.

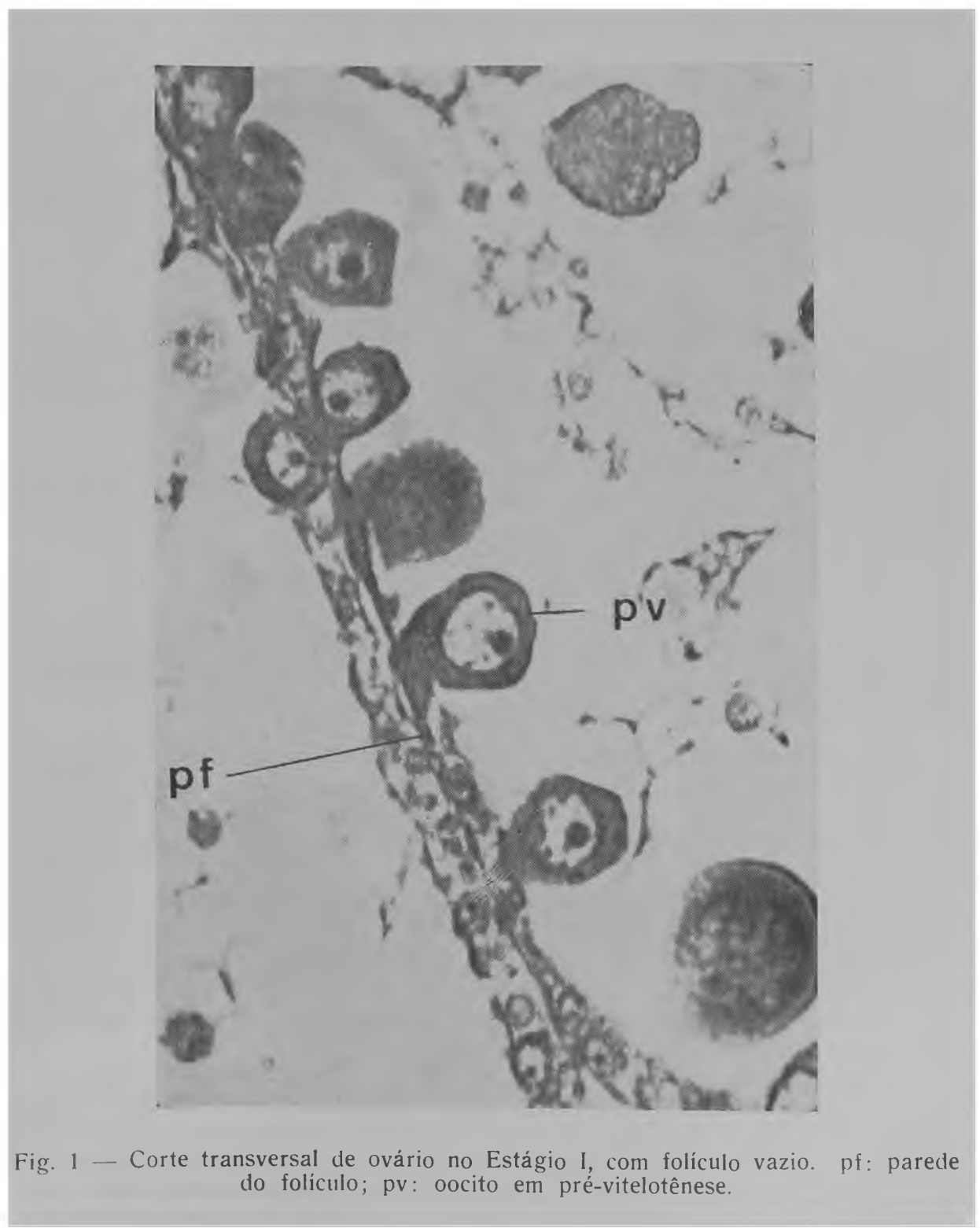


Este estágio pode ser subdividido em:

IIIA: Folículos totalmente preenchidos por gametas.

IIIB : Esvaziamento parcial dos folículos.

IIIC: Fase de restauração da gônada, quando há maior nitidez dos folículos.

IIID: Fim da gametogênese, folículos vazios.

Estágio I Aparecimento de esboços foliculares.

No início do desenvolvimento das gônadas, ou ainda na fase IIID, surgem certas zonas foliculares de elementos germinativos, que são as "células-mães" das gônias, as gônias primárias e as espermatogônias ou oogônias. Elas provêm da diferenciação dos elementos precedentes caracterizados por tamanho reduzido e material cromático fortemente corado. Esses elementos são pouco numerosos neste estágio.

\section{Evolução das gônadas nas fêmeas}

As pequenas oogônias, crescem até 7 a $9 \mu \mathrm{m}$, com aumento simultâneo do diâmetro do núcleo $(5$ a $7 \mu \mathrm{m})$ e do nucléolo, e a densa cromatina transforma-se em um retículo fino. As células vão iniciar sua divisão e há células que permanecem presas na parede.

Nesta fase há elementos germinativos em diferentes estágios de evolução: células-mães, oogônias primárias, oogônias em mitose e oogônias em pré-vitelogênese (Fig. 1).

\section{Evolução das gônadas nos machos}

Os fenômenos são comparáveis aos já descritos para as oogônias e aos descritos em Mytilus por Lubett (1959). Verifica-se crescimento e divisão da espermatogônia, o núcleo atingido de 4 a $5 \mu \mathrm{m}$.

Este estágio (I) corresponde à fase de evolução genital em que predominam as oogônias ou espermatogônias (crescimento e multiplicação).

Estágio II Multiplicação das gônias: Oogênese e espermatogênese.

Oogênese. A maioria das oogônias situadas na parede conjuntiva dos folículos entra em meiose. Algumas porém permanecem em repouso, não completando seu desenvolvimento. Os oócitos crescem e esse crescimento pode ser dividido em duas etapas, com características citológicas bem diferentes: a pré-vitelogênese e a vitelogênese, as quais coexistem no mesmo folículo (Fig. 2).

Pré-vitelogênese. O crescimento do oócito inicia-se, porém, é lento. As células atingem de 10 a $20 \mu \mathrm{m}$ de diâmetro e encontram-se fortemente presas às paredes do folículo. Surgem no núcleo numerosos nucléolos acessórios, localizados próximo à membrana nuclear e a cromatina forma finas trabéculas que conferem ao núcleo um aspecto reticulado. 


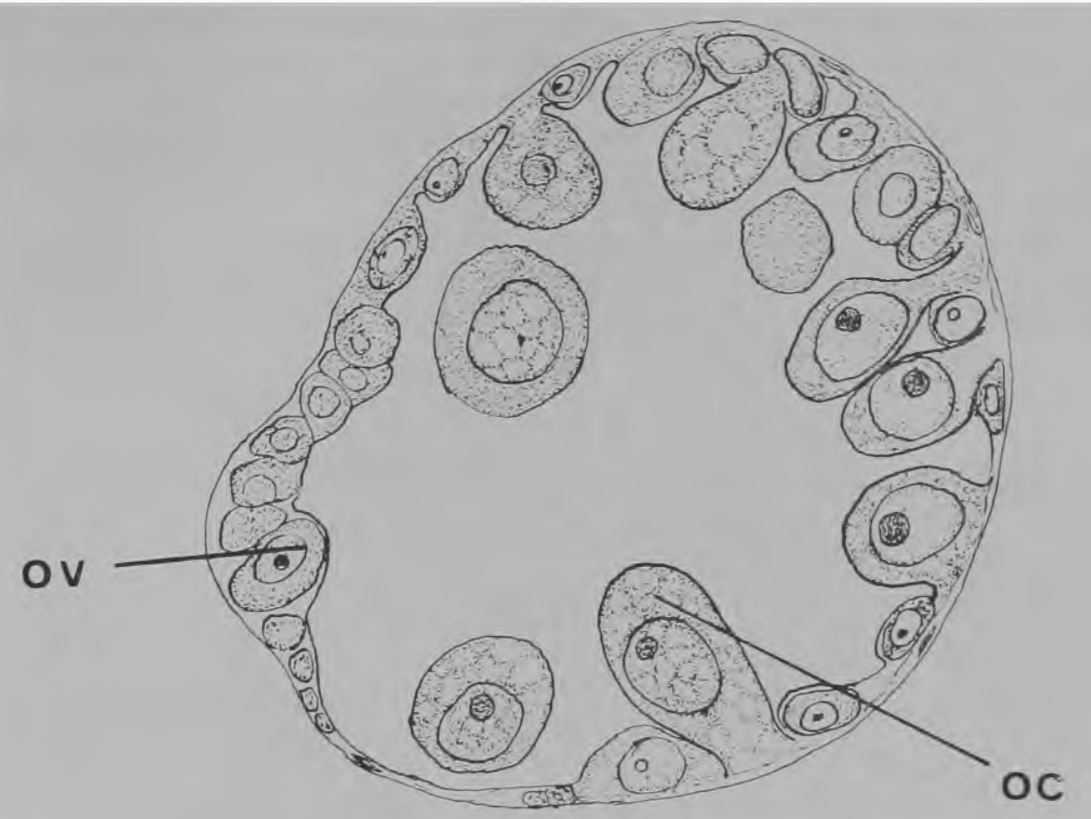

Fig. 2 - Corte transversal de ovário, mostrando um folículo durante o período de restauração da gônada. oc: oócito; ov: oogônia.

Vitelogênese. O crescimento do oócito é mais intenso nesta fase: ele se torna elíptico e está preso à parede conjuntiva por uma zona peduncular. O núcleo localiza-se na região mais globosa que ocupa o lúmen do folículo. Os oócitos, cortados transversalmente, têm contorno poligonal e são justapostos entre si. $\mathrm{O}$ núcleo cresce muito, atingindo até $30 \mu \mathrm{m}$ em uma célula de $70 \mu \mathrm{m}$. O nucléolo também cresce e a cromatina diminui bastante, não apresentando as trabéculas da fase anterior.

Espermatogênese. As espermatogônias dispõem-se nos ácinos da gônada em uma ou duas camadas periféricas, como Lubett (1959) observou em Mytilus. Elas entram em meiose e todos os estágios da espermatogênese são visíveis em zonas sucessivas, embora, às vezes, as relações entre elas, como mencionou Lunetta (1969), não sejam fáceis de estabelecer. 
Os espermatócitos de $1 .^{*}$ ordem são facilmente identificáveis pelo seu tamanho, quando comparados com os de $2 a^{a}$ ordem. O diâmetro da célula é de 7 a $8, \mu \mathrm{m}$ e as de $2 .^{\mathrm{a}}$ ordem medem de 3 a $4 \mu \mathrm{m}$.

Os espermatócitos de $2 .^{3}$ ordem têm citoplasma muito pouco abundante e as espermátides, com diâmetro menor do que 2,5 a $3,5 \mu \mathrm{m}$, são também muito pobres em citoplasma (Fig. 3).

Os espermatozóides formam-se no centro do folículo. A cabeça tem a forma de vibrião, onde a cromatina se condensa e tinge-se fortemente pela hematoxilina. O flagelo mede de 30 a $35 \mu \mathrm{m}$ de comprimento.

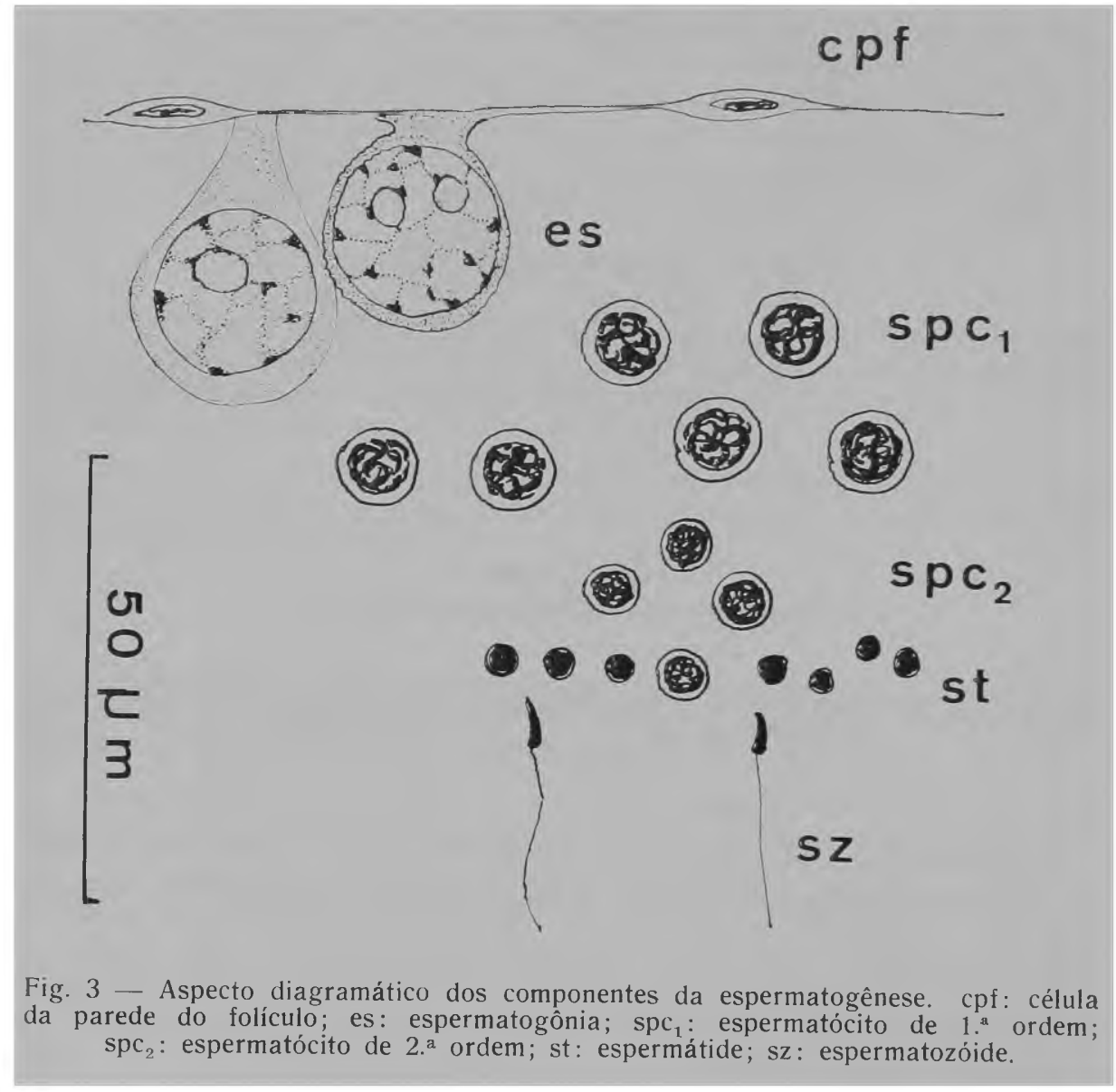

Estágio III Período de reprodução.

Estágio IIIA $A_{1}$ Com folículos totalmente preenchidos com gametas.

Machos. Os ácinos da gônada apresentam ainda uma porcentagem alta de espermatogônias, espermatócitos de $1 .^{a}$ e $2 .^{a}$ ordem e de espermátides. As mitoses são numerosas e os espermatozóides encontram-se 


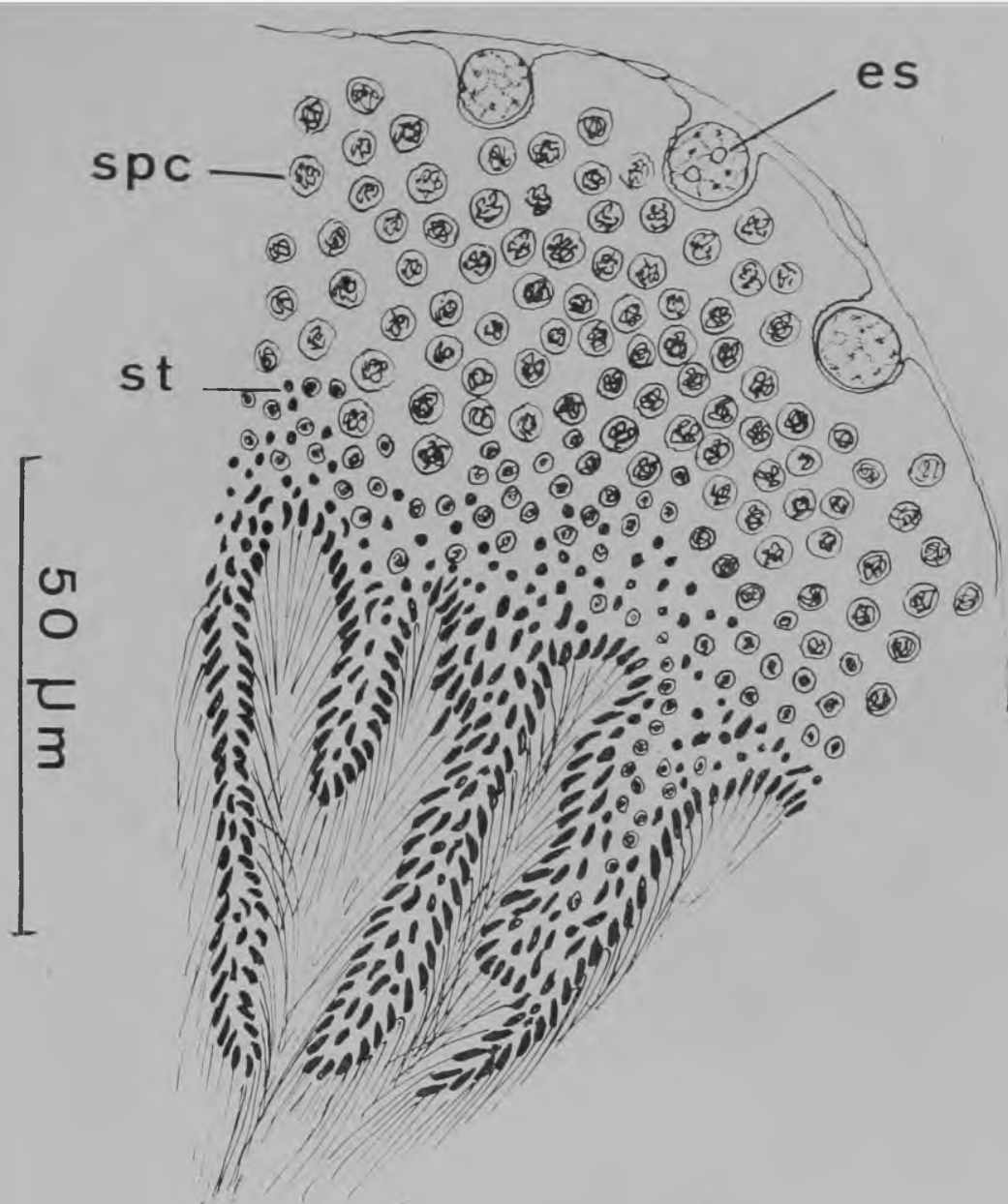

Fig. 4 - Corte transversal do testículo com os espermatócitos dispostos em camadas (Estágio $\left.I I I A_{1}\right)$. es: espermatogônia; spc: espermatócito; st: espermátide.

dispostos radialmente, com as caudas dirigidas para o eixo central do folículo (Fig. 4).

Fêmeas. Muitos oócitos completaram seu crescimento, medindo até 60 a $70 \mu \mathrm{m}$ de comprimento, havendo porém numerosos oócitos em vitelogênese, os quais apresentam contorno poligonal (Fig. 5).

\section{Estágio $I I I A_{2}$.}

Machos. Os folículos da gônada apresentam algumas gônias e uma camada periférica de espermatogônias. Os espermatócitos de $10^{8}$ e $2 .^{a}$ ordem são raros, assim como as espermátides. A luz do folículo encontra-se preenchida de espermatozóides funcionais. 


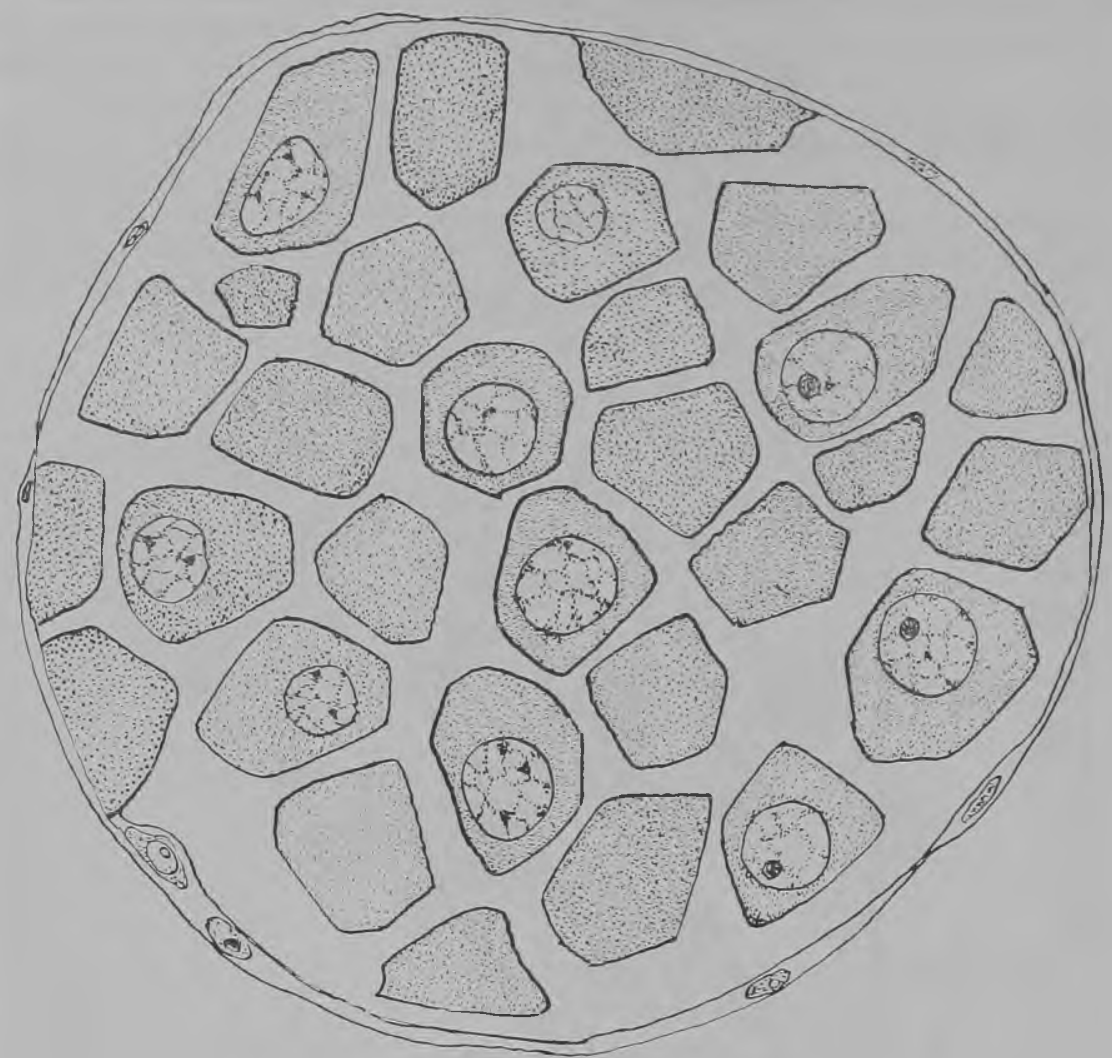

$100 \mu \mathrm{m}$

Fig. 5 - Corte transversal do ovário no Estágio IIIA, mostrando o folículo com oócitos de contorno poligonal.

Fêmeas. A forma dos oócitos modifica-se ligeiramente, seu contorno torna-se mais regular, mais piriforme e eles encontram-se presos à parede conjuntiva. O nucléolo desaparece.

Estágio IIIB. Esvaziamento parcial ou total da gônada.

As espermatogônias subsistem ao longo das paredes dos folícilos e, às vezes, em certas regiões, também os espermatócitos de $1 .^{\mathrm{a}}$ ordem. $\mathrm{Na}$ zona distal do folículo há gônias que se diferenciam para formar espermatogônias e há também espermatogônias em multiplicação (Fig. 6). 


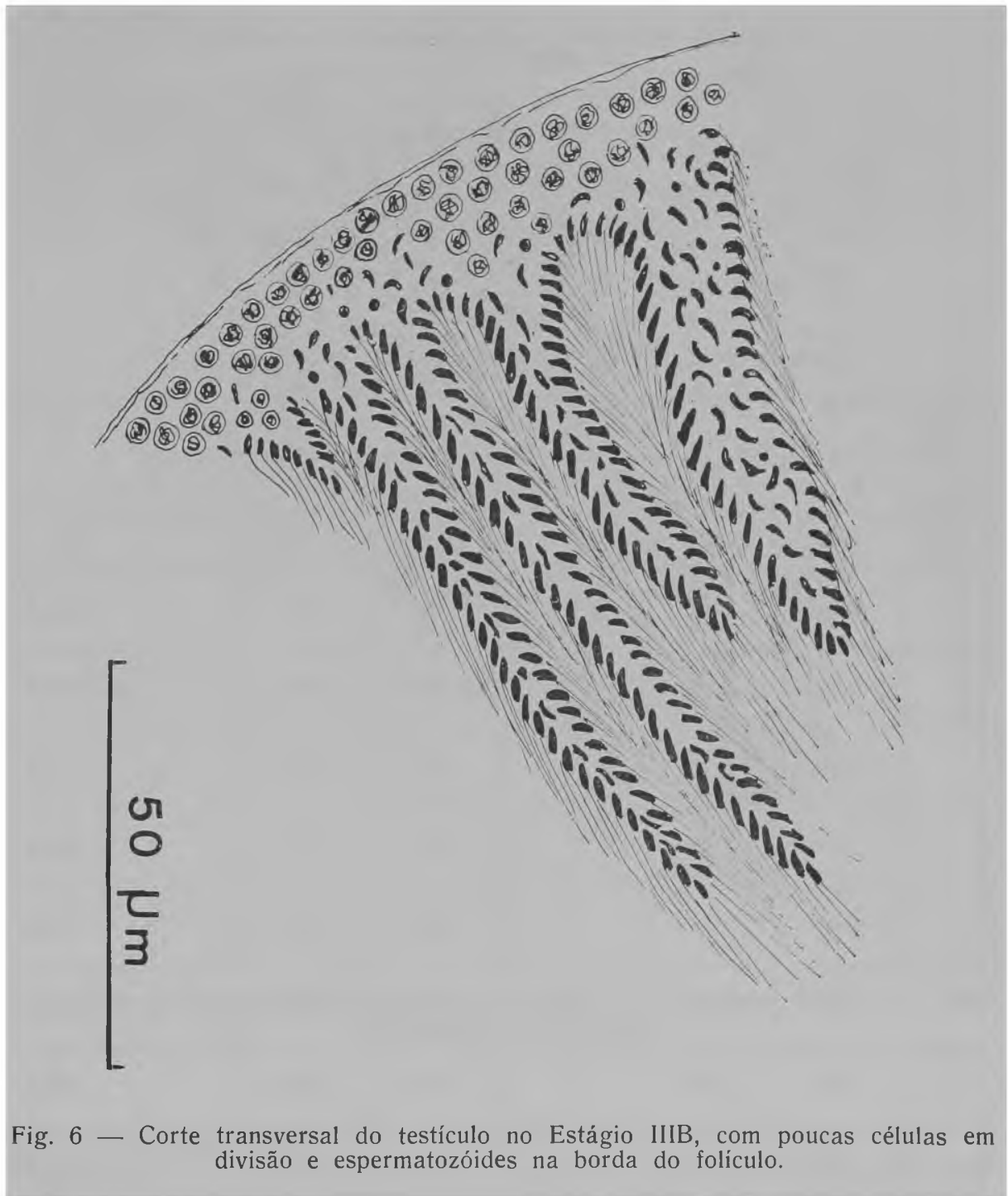

Um certo número de oócitos pequenos não é eliminado e observam-se as gônias responsáveis por novos fenômenos de gametogênese.

Estágio IIIC. Fase de restauração da gônada.

Ela caracteriza-se pela ausência de gametas maduros nos folículos. As espermatogônias renovam-se graças à divisão das células-mães, que permaneceram em repouso desde o processo precedente. Divisões ativas surgem em espermatogônias até espermatozóides, sendo o número de espermatócitos, porém, muito grande (Fig. 7). 


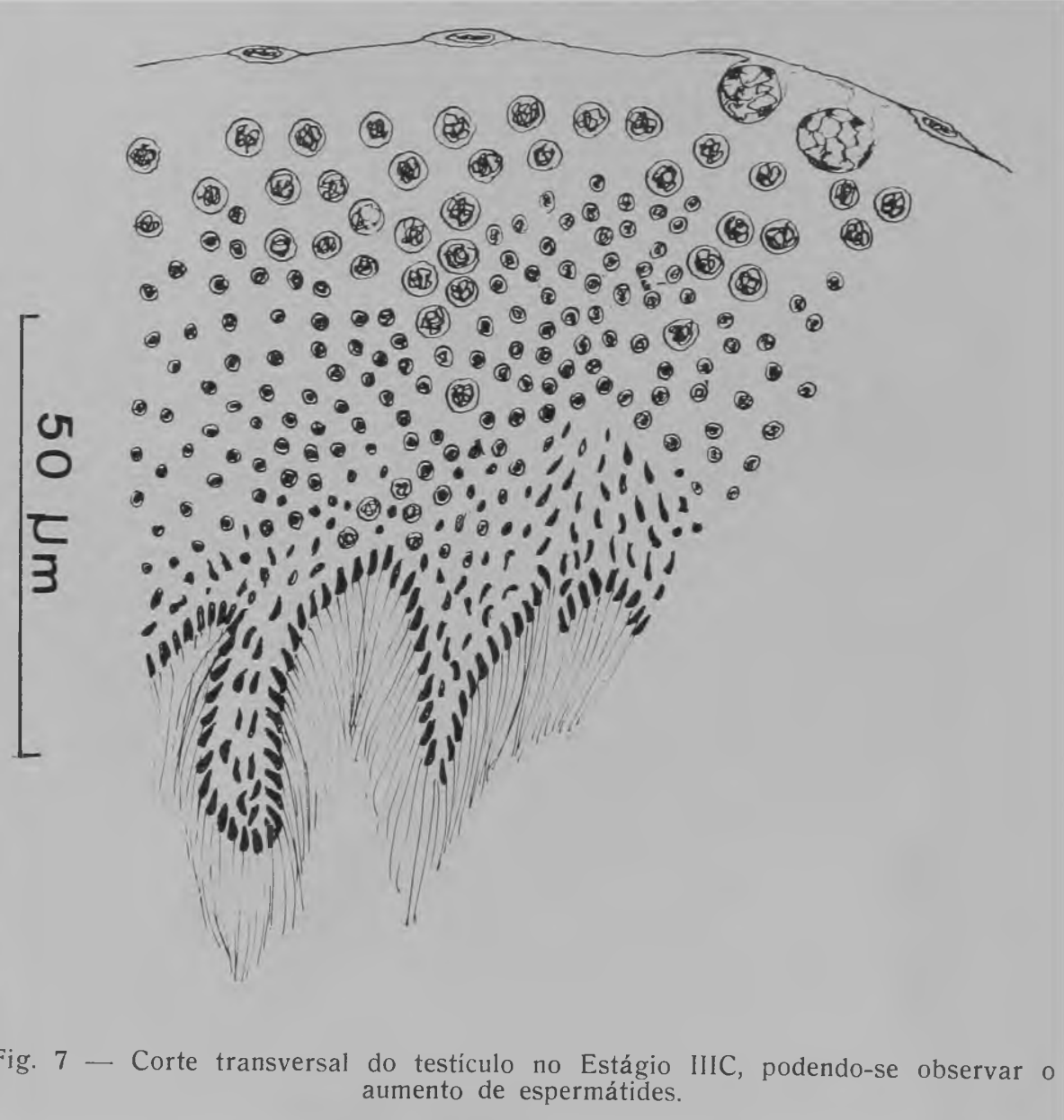

Nas fêmeas as células-mães dividem-se para formar numerosas oogônias que, posteriormente, entrarão em pré-vitelogênese. O crescimento de certos oócitos será inibido pelo desenvolvimento mais rápido de outros e permanecerão na gônada como material pronto a se desenvolver na próxima estação sexual (Fig. 8).

Estágio IIID. Fim da gametogênese.

A gametogênese termina e os folículos encontram-se praticamente vazios, com exceção de alguns gametas residuais e de amebócitos. Em Mytilus o tecido conjuntivo mostra lacunas foliculares, com gametas residuais, que serão fagocitados pelos elementos sangüíneos, o que não ocorre em A. brasiliana (Fig. 9). 


\section{Análise e Freqüência dos Diferentes Estágios}

A fim de determinar a freqüência dos diferentes estágios, vários indivíduos da mesma população foram examinados cada 30 dias. Cortes da gônada foram feitos em cerca de 10 machos e 10 fêmeas, sendo examinados, de junho de 1970 a julho de 1972, cerca de 240 machos e 240 fêmeas. Os resultados destas análises encontram-se nas Tabelas I e II.

TABELA I e II

Porcentagem de $A$. brasiliana nos diferentes estágios sexuais

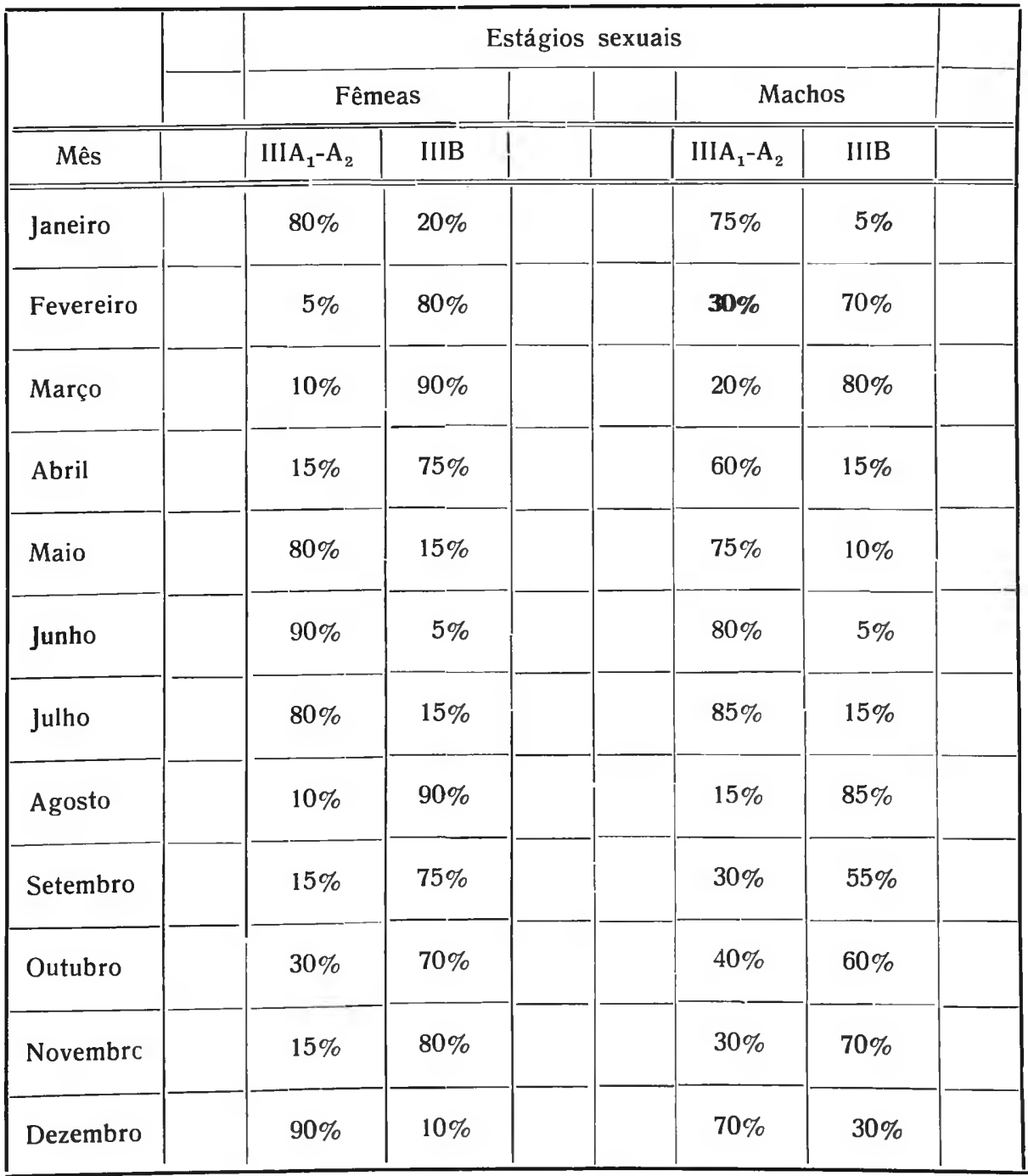




\section{Ciclo Anual nos anos de 1970 a 1972}

Os resultados obtidos nos dois anos de estudos foram praticamente iguais. As características fundamentais correspondentes a cada mês do ano são as seguintes:

Janeiro. A gametogênese é intensa, encontrando-se $75 \%$ dos machos e $80 \%$ das fêmeas da população no Estágio IIIA. Um pequeno número de animais, $5 \%$ dos machos e $20 \%$ das fêmeas, elimina seus gametas parcial ou totalmente. Quase todos os folículos apresentam espermatozóides.

Fevereiro. Cerca de $80 \%$ das fêmeas e $70 \%$ dos machos encontram-se no Estágio IIIB, eliminando total ou parcialmente seus produtos. Um pequeno número de animais, cerca de $10 \%$ das fêmeas e praticamente nenhum macho, está em fase de recuperação das gônadas e $5 \%$ estão na fase de multiplicação. Loosanoff (1937) observou que apesar da diminuição da temperatura, em novembro e dezembro, o desenvolvimento dos

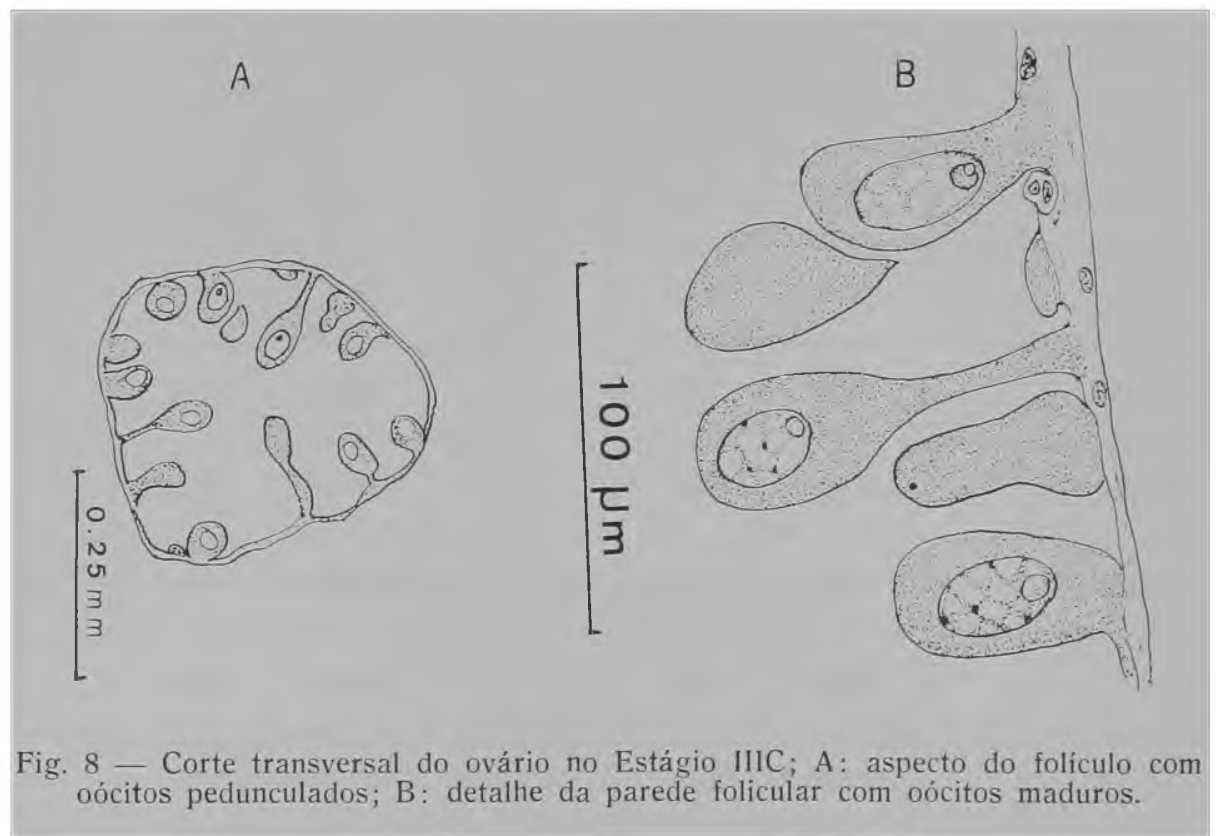

gametas de Venus mercenaria continua normalmente. Os ovários contêm poucos ovócitos, muito pequenos, que são característicos em outubro.

Março. Elevado número de indivíduos no Estágio IIIB $(90 \%$ das fêmeas e $80 \%$ dos machos) encontra-se em emissão total ou parcial. $O$ estágio IIIA é mais evidente nos machos $(20 \%)$ que nas fêmeas $(10 \%)$.

Abril. A eliminação intensa de gametas continua nas fêmeas $(75 \%)$, sendo bastante diminuida nos machos $(15 \%)$. Nestes continua a multiplicação dos gonócitos, cuja proporção $(60 \%)$ é maior que a do mês anterior. A restauração dos folículos é evidente em parte dos machos ou das fêmeas, em proporção de $10 \%$ a $25 \%$ respectivamente. 


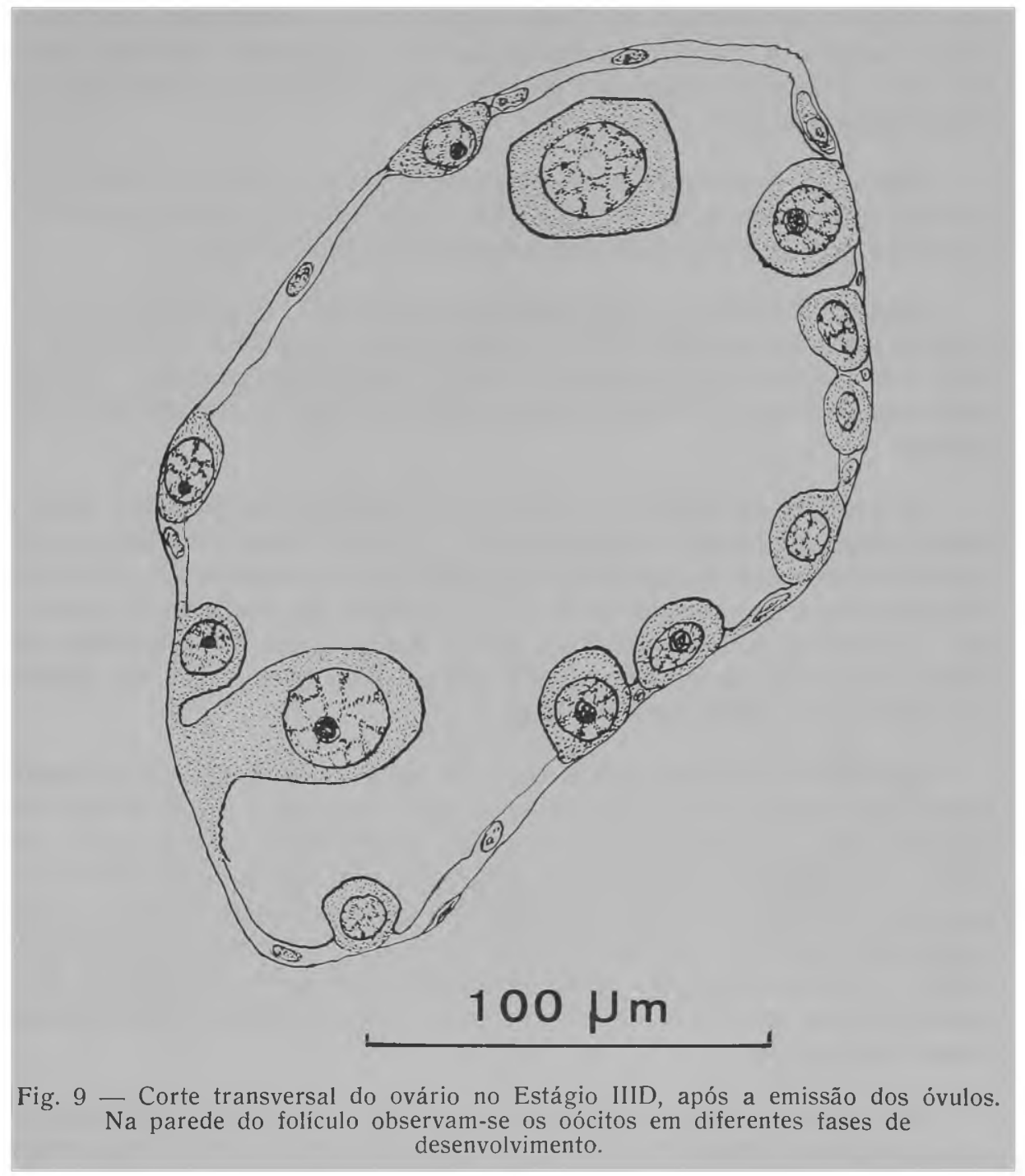

Maio. A gametogênese inicial dos machos continua na proporção de $75 \%$, mais elevada em relação ao mês anterior. As fêmeas apresentam um aumento considerável, com a proporção de $80 \%$. Cerca de $15 \%$ das fêmeas e $10 \%$ dos machos encontram-se com folículos praticamente vazios.

Junho. A gametogênese continua, com o preenchimento dos folículos. A proporção, $90 \%$ das fêmeas e $80 \%$ dos machos, aumentou em relação à anterior. Fêmeas e machos encontram-se com folículos vazios, mas a proporção agora é menor: $5 \%$ das fêmeas e 5\% dos machos.

Os resultados de Loosanoff (1937) mostraram que nos machos a espermatogênese é incipiente em maio, com temperatura de 10 a $13,5^{\circ} \mathrm{C}$. 
Ao atingir a temperatura $15^{\circ} \mathrm{C}$ ela se acelera, de forma que em junho, julho e agosto os animais apresentam-se com as gônadas repletas. Este fato não se verifica entre nós por não haver mudança tão abrupta da temperatura (Gráfico 1).

Julho. A gametogênese continua e $80 \%$ das fêmeas e $85 \%$ dos machos apresentam-se no Estágio IIIA. A emissão de gametas acentuase, com a proporção de $15 \%$ das fêmeas e $15 \%$ dos machos.

Agosto. Eliminação muito intensa de gametas. A proporção de fêmeas e machos no Estágio IIIB é muito grande, com $90 \%$ das fêmeas e $85 \%$ dos machos com eliminação total ou parcial dos gametas. Apenas $10 \%$ das fêmeas e $15 \%$ dos machos estão na fase de multiplicação das gônias.

Os machos examinados mostraram as gônadas com folículos distendidos, contendo poucas células sexuais. A parte central do lúmen está vazia e poucos espermatozóides estão próximos às paredes dos folículos. Espermátides e espermatócitos de $1 .^{7}$ e $2 .^{\text {a }}$ ordem são praticamente ausentes. Loosanoff (1937) verificou que a maior parte da população de Venus mercenaria descarrega seus produtos neste mês, o que ele atribui ao aumento da temperatura da água.

Setembro. Continua a eliminação de gametas, com $75 \%$ das fêmeas nesta fase e a proporção dos machos abaixa para 55\%. Das fêmeas há $10 \%$ na fase de restauração da gônada e nos machos a proporção é de $15 \%$. No estágio de multiplicação (IIIA) há $15 \%$ das fêmeas e $30 \%$ dos machos. Diminui o número de óvulos não eliminados nos ovários, sendo alguns normais em aparência, como em Venus mercenaria (Loosanoff, 1937). Aparentemente eles serão eliminados mais tarde, de maneira normal e de uma certa forma até novembro, o que se verificou também com Venus mercenaria.

Nos machos, após a eliminação de gametas, as gônadas multiplicamse para produzir células sexuais para o próximo ano. Os folículos estão preenchidos por células espermatogenéticas em diferentes estágios de desenvolvimento. Ao longo das paredes dos folículos numerosas espermatogônias multiplicam-se, formando 2 ou 3 camadas de células. Surgem os espermatócitos de $1 .^{\mathrm{a}}$ e $2 .^{\circ}$ ordem e espermátides.

Outubro. Continua a eliminação de gametas, com $70 \%$ das fêmeas e $60 \%$ dos machos nesta fase, enquanto que os $30 \%$ das fêmeas e os $40 \%$ dos machos restantes estão na fase IIIA.

Novembro. Continua a eliminação de gametas com $80 \%$ das fêmeas e $70 \%$ dos machos nesta fase, enquanto que $15 \%$ das fêmeas restantes 


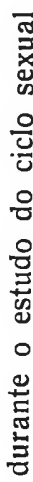
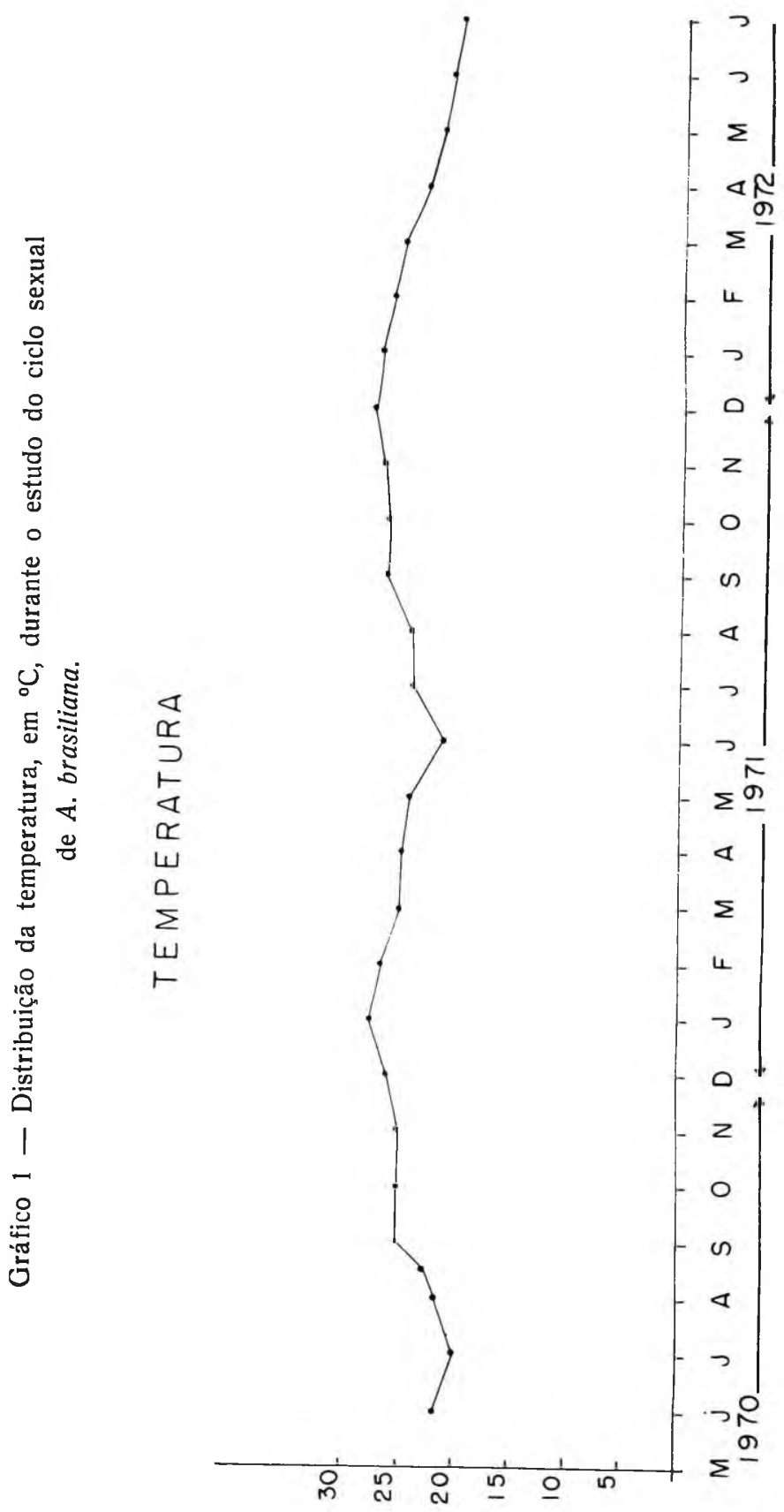

ว. $\forall y \cap 1 \forall \forall \exists d W \exists \perp$ 
estão na fase IIIA e 5\% na fase de restauração da gônada. Os $30 \%$ restantes dos machos encontram-se na fase IIIA.

Dezembro. A gametogênese intensifica-se muito, com $90 \%$ das fêmeas e $70 \%$ dos machos nesta fase, enquanto que apenas $10 \%$ das fêmeas e $30 \%$ dos machos restantes eliminam seus gametas parcial ou totalmente. Há grandes oócitos ocupando muito espaço livre dos folículos, havendo alguns em estágio muito incipiente de desenvolvimento. Em época de multiplicação celular intensa, há poucas células nutritivas, como observou Loosanoff (1937), em Venus mercenaria. Nos machos haverá um grande número dessas células, demonstrando aparentemente, uma importância maior no ciclo metabólico do testículo. Há espermatócitos de $1 .^{\mathrm{a}}$ e $2 .^{\mathrm{a}}$ ordem e espermátides em grande quantidade.

A espermatogênese continua e espermatozóides são formados em muitos folículos.

\section{CONCLUSÕES E DISCUSSÃO}

Com base nos dados das Tabelas I e II e nos Gráficos 1 e 2 verificamos o seguinte:

a. Há um sincronismo, tanto nos machos como nas fêmeas, apesar de haver algumas diferenças entre as seqüências do ciclo sexual. Ele é bem observado nos Estágios IIIA e IIIB, sendo mais evidente no último, de emissão total dos gametas.

b. Foram observados dois períodos mais importantes de emissão de gametas, nos anos 1970 a 1972, isto é, no outono (fevereiro-marçoabril) e na primavera (agosto-setembro-outubro-novembro). A porcentagem de emisão é equivalente nos dois períodos, mas o da primavera é mais longo.

c. Ocorre eliminação de gametas nos períodos intermediários, mas apenas em pequena parte da população. A observação de Narchi (1965) refere-se sem dúvida a exemplares aqui incluídos.

d. Não há um período de repouso sexual definido, como ocorre em Mytilus.

O ciclo sexual de A. brasiliana é praticamente contínuo, com períodos de reprodução mais evidentes em fevereiro a abril e agosto a novembro, e intervalos com emissões de gametas sem muita importância. A atividade sexual é diminuída em dezembro a janeiro (verão) e em julho (inverno). Os gráficos evidenciam que nos estágios em que a gametogênese intensa é minima, a eliminação de gametas é máxima. Loosanoff (1937) demonstrou a existência de gametogênese ativa e a produção de gametas, sem un período de recuperação, em $V$ mercenaria, assim como em Ostrea virginica, que ocorre na mesma área.

Nas principais épocas de emissão de gametas as porcentagens mais altas foram em março e agosto.

A expulsão de gametas em ambos os sexos é contínua e sempre notamos uma porcentagem maior de fêmeas eliminando os gametas em março. e agosto. 
As fêmeas nunca apresentam eliminação completa de óvulos e como observou Ansell (1961), em Venus striatula, alguns ovócitos residuais permanecem no ovário até o fim do período de desova. Fato semelhante foi observado em Venerupis pullastra (Quayle, 1952), Venus mercenaria (Loosanoff, 1937a) e Cyprina islandica (Loosanoff, 1953).

Em A. brasiliana o desenvolvimento de ovócitos jovens inicia-se antes do término da desova. O ovário passa da condição de desova para o início do desenvolvimento, sem que haja um período de repouso, como é verificado em Filibranchiata.

Nos machos, as gônadas examinadas após a eliminação, continham elevado número de espermatozóides. É muito difícil distinguir entre os animais maduros aqueles que não eliminaram seus gametas. Estes, podem ser encontrados durante todo o ano como Ansell (1961) verificou em Venus striatula.

De modo geral, os trabalhos feitos no hemisfério norte, com Filibranchiata, entre os quais cito Loosanoff (1962) com Ostrea edulis, Loosanoff (1969) com Crassostrea virginica, Berg (1969) com Crassostrea virginica e Crassostrea gigas, demonstram a maior proporção de desova entre julho e agosto.

Os trabalhos com Eulamellibranchiata, entre os quais os de Weymouth (1923), Loosanoff (1937) e Ansell (1961) determinam o período.de desova de Tivela stultorum em julho a setembro, Mactra solidissima em junho-julho, Venus mercenaria em agosto-setembro, $V$ striatula, $V$ ovata, $V$ casina em maio, $V$ fasciata em fevereiro a julho, $V$ decussata em julho, Venerupis pullastra em junho-julho e Gafrarium minimum em junho.

Trabalhos no hemisfério sul, como o de Nielsen (1964), determinam para Katelysia (Eulamellibranchiata) os períodos de setembro, novembro e março. Justamente os meses onde encontrei a porcentagem maior de indivíduos em desova no litoral de São Paulo.

É interessante notar que as conclusões gerais são ligeiramente diferentes das encontradas por Lunetta (1969), para Mytilus. Assim, enquanto que neste gênero a emissão de gametas efetuou-se em abril-maio e junho-setembro, em Anomalocardia ocorreu em fevereiro-abril e agostonovembro. No entanto, como em outro Veneridae, Venus mercenaria (Loosanoff, 1937a), durante todo o ano ocorreu emissão de gametas.

\section{AGRADECIMENTOS}

Desejo expressar meus agradecimentos à Fundação de Amparo à Pesquisa do Estado de São Paulo, pelo auxílio recebido. Agradeço também ao Sr. Fernando Frassei, cuja ajuda nas coletas e na preparação das lâminas histológicas possibilitaram a realização deste trabalho. 


\section{REFERÊNCIAS BIBLIOGRÁFICAS}

ANSELL, A.D. - 1961 - Reproduction, Growth and Mortality of Venus striatula (da Costa) in Kames Bay, Millport, Scotland. J. mar. biol. Assoc. U. K. 41: 191-215.

BERG Jr., C.J. - 1969 - Seasonal gonadal changes of adult oviparous oysters in Tomales Bay, California. Veliger 12(1): 27-36, 3 pl.

CHIPPERFIELD, P.N.J. - 1953 - Observation on the breeding and settlement of Mytilus edulis (L.) in British waters. J. mar. biol. Assoc. U. K. 32: 449-476.

LOOSANOFF, V.L. - 1937 - Development of the primary gonad and sexual phases in Venus mercenaria Linnaeus. Biol. Bull. Woods Hole 72(3): 389-406.

LOOSANOFF, V.L. - 1937a - Seasonal gonadal changes of adult clams, Venus mercenaria (L.). Biol. Bull. Woods Hole 72(3): 406-416.

LOOSANOFF, V.L. - 1953 - The reproductive cycle in Cyprina islandica. Biol. Bull. Woods Hole 104: 146-155.

LOOSANOFF, V.L. - 1962 - Gametogenesis and spawning of the European oyster Ostrea edulis, in waters of Maine. Biol. Bull. 122(1): 86-94.

LOOSANOFF, V.L. - 1969 - Maturation of gonads of oysters, Crassostrea virginica, of different geographical areas subjected to relatively low temperatures. The Veliger $11(3)$ : 153-163.

LUBETT, P. - 1959 - Recherches sur le cycle de l'emission des gamètes chez les Mytilidés et les Pectinidés. Thèse Paris, 162 pp. Paris.

LUNETTA, J.E. - 1969 - Fisiologia da reprodução dos mexilhões (Mytilus perna Mollusca, Lamellibranchiata). Bol. Fac. Fil. Ciências e Letras U.S.P n.० 324, Zool. \& Biol. Mar. 26: 33-111.

NARCHI, W. - 1965 - Preliminary contribution of the functional morphology of Anomalocardia brasiliana (Bivalvia, Veneridae) from the littoral of São Paulo. An. Acad. Brasileira de Ciências 37.

NARCHI, W. - 1972 - Comparative study of the functional morphology of Anomalocardia brasiliana (Gmelin, 1791) and Tivela mactroides (Born, 1778) (Bivalvia, Veneridae). Bull. mar. Science 22(3): 643-670.

NARCHI, W. - 1974 - Aspectos ecológicos e adaptativos de alguns bivalves do litoral paulista. Papéis Avulsos Zool., São Paulo, 27(19): 235-262.

NIELSEN, B.J. - 1964 - Studies of the genus Katelysia Romer 1857 (Mollusca Lamellibranchiata). Mem. Nat. Mus. Melbourne 26: 219-257. 


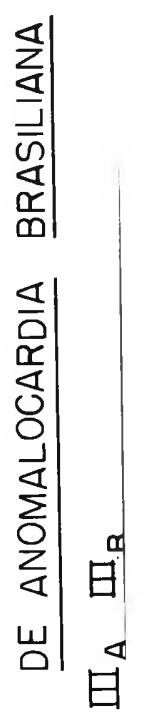

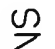

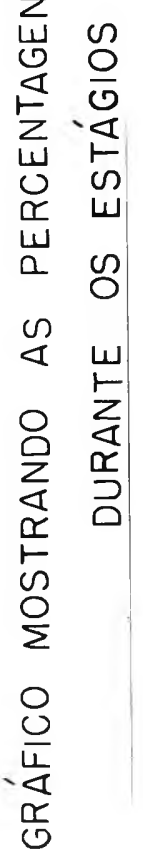



ORTON, J.H., A.J. SOUTHWARD \& J.M. DODD - 1956 - Studies on the biology of limpets; the breeding of Patella vulgata L. in Britain. J. mar. biol. Assoc. U. K. 35: 149-176.

QUAYLE, D.B. - 1952 - Structure and biology of the larva and spat of "Venerupis pullastra (Montagu)" Trans. roy. Soc. Edinb. 62(1): 255-297, 1 pl.

WEYMOUTH, F.W. - 1923 - The life history and growth of the Pismo clam (Tivela stultorumi). Calif. Fish Game Bull. n. 7: 5-120. 
